\title{
TESTING PURCHASING POWER PARITY UNDER THE NULL HYPOTHESIS OF GO-INTEGRATION
}

\author{
Eric O'N. Fisher and Joon Y. Park
}

When Cassel (I916) first proposed the notion of purchasing power parity, he presented evidence that established a correlation between the exchange rates and price indices of France, Germany, Sweden, Russia, and the United Kingdom. Cassel derived the inflation rates of the non-English countries in his sample from the relevant bilateral exchange rates and the price index for the United Kingdom. It is striking to the modern eye that the price indices he computed appear not to be stationary. Since these data covered the first two years of the first war, it is not surprising that they demonstrate high rates of inflation. During the modern period of floating exchange rates, the major industrial countries have also experienced persistent inflation; hence, their price indices are not stationary. This poses particular problems for the typical tests of Cassel's ideas.

Indeed, tests of purchasing power parity have been an area in which the new techniques of time series econometrics have found ready application. These tests examine three time series: a bilateral nominal exchange rate and a pair of price indices. If any of these series is not stationary, tests based upon the classical assumptions are inappropriate. This has led a spate of economists to reinterpret the traditional test of purchasing power parity as a test for cointegration. This paper tests for purchasing power parity under the null hypothesis that exchange rates and prices are co-integrated.

Because there have been so many recent applications of co-integration tests within international finance, it behooves us to differentiate our product. We are approaching these tests from three novel perspectives. First, our tests are based upon the null hypothesis of co-integration. Second, we analyse a wide cross-section of data: the exchange rates and price indices of every major industrial country over the entire modern period of floating rates. Third, we estimate error correction mechanisms in order to get a sense of the dynamic adjustments of these systems.

The tests presented below permit one to draw three conclusions. First, a weak form of purchasing power parity describes the behaviour of almost all the major currencies but the Canadian and American dollars quite well. ${ }^{1}$ This implies that value of the American dollar has diverged arbitrarily far from the fundamentals that Cassel first explored. Second, there is little evidence that these real exchange rates are stationary. Third, the adjustment to dis-

* The authors would like to thank two anonymous referees, Gary Barinshtein, John Cochrane, and seminar participants at the University of Chicago for helpful comments on earlier drafts of this paper. The authors will make available at cost a computer diskette with the data, the tests, and all the results described in the text.

1 Frenkel (198I) found a similar result for three European currencies during the 1970s. 
equilibrium occurs in the markets for foreign exchange, not in the markets for goods. This is concrete evidence that goods prices are indeed stickier than asset prices.

The work of Isard (I977) showed that the micro-economic foundations of purchasing power parity were suspect; he used traditional econometric techniques. Meese and Singleton ( I982) first applied unit root tests to exchange rate data. Corbae and Ouliaris (I986) and Baillie and Bollersley (I989) are other examples of this research. Enders (I988) and Edison and Fisher (I99 I) are recent applications of co-integration tests in international finance.

It is important to state that the applied literature in international finance has not found much evidence of co-integration among the currencies and price indices of the major industrial countries during the modern period of floating exchange rates. This is a broad rejection of purchasing power parity, but almost all of this work has been based upon the null hypothesis that Cassel's original idea is false.

\section{A SiMPLE MODEL OF EXGHANGE RATES AND PRICES}

Consider two countries in a larger world economy. Prices in the home country are described by

$$
p_{t}=\alpha p_{1, t}+(\mathrm{I}-\alpha) p_{2, t}+u_{t},
$$

where $p_{t}$ is the logarithm of the domestic price index at time $t, p_{1, t}$ is the logarithm of an index of traded goods prices at time $t, p_{2, t}$ is an analogous index for non-traded goods, and $\left\{u_{t}\right\}$ is stationary. The parameter $\alpha \in(\mathrm{O}, \mathrm{I})$ is the proportion of traded goods in the index. The error term includes third country effects, and these are uncorrelated with the prices of both non-traded goods and goods traded bilaterally between the countries in question. The econometrician can observe $p_{t}$ but cannot measure $p_{1, t}$ and $p_{2, t}$ independently.

Assume further that both traded goods prices and non-traded goods prices are integrated of order one; we shall maintain that these prices have a deterministic drift term. This captures the notion that the 'natural' rates of inflation of both domestic prices and traded goods prices are not zero; further, this implies that some part of any inflation shock represents a permanent increase in the price level. The data generating process for the logarithm of non-traded goods prices in the domestic economy is

$$
p_{2, t}=\beta p_{1, t}+v_{t}
$$

where $\beta>0$ and $\left\{v_{t}\right\}$ is integrated of order zero. Since $\left\{p_{1, t}\right\}$ and $\left\{p_{2, t}\right\}$ are integrated of order one, (2) states that these series are co-integrated. If $\beta>$ I, there is a deterministic appreciation of the real exchange rate, and if $0<\beta<\mathrm{I}$, then the real exchange rate is depreciating. The error term $v_{t}$ is a transitory country-specific shock to the real exchange rate.

The data generating processes for foreign prices $\left\{p_{1, t}^{*}\right\}$ and $\left\{p_{2, t}^{*}\right\}$ are analogous. Let $\alpha^{*}$ and $\beta^{*}$ be the relevant parameters for the foreign country; it is not 
necessary to assume that $\alpha=\alpha^{*}$ or that $\beta=\beta^{*}$. The fact that the two countries may have different rates of depreciation of their real exchange rates captures the notion that real economic variables affect the two economies in asymmetric ways. Technology shocks and changes in preferences are two such forces.

An aggregate version the law of one price holds for the goods that are traded between these two countries. This is captured by the relationship

$$
p_{1, t}=e_{t}+p_{1, t}^{*},
$$

where $e_{t}$ is the domestic currency price of a unit of foreign exchange at time $t$. An increase in $e_{t}$ is a depreciation of the domestic currency. Note that (3) is an identity between variables that the econometrician cannot observe.

Using (I), (2), (3), and their analogs, we may write

$$
e_{t}=\gamma p_{t}+\gamma^{*} p_{t}^{*}+\eta_{t}
$$

where $\left\{\eta_{t}\right\}$ is integrated of order at most zero. Since the price sub-indices are all integrated of order one and all have deterministic drift components, $\left\{p_{t}\right\}$ and $\left\{p_{t}^{*}\right\}$ inherit these properties. Hence, (4) implies that the series $\left\{e_{t}\right\},\left\{p_{t}\right\}$, and $\left\{p_{t}^{*}\right\}$ are co-integrated. It is possible to show that $\gamma=\mathrm{I}$ if and only if $\beta=\mathrm{I}$. Likewise, $\gamma^{*}=-\mathrm{I}$ if and only if $\beta^{*}=\mathrm{I}$. Hence, the normalised co-integrating vector is $(\mathrm{I}, \mathrm{I},-\mathrm{I})^{\prime}$ if and only if neither country experiences a change in its real exchange rate.

If either $\gamma \neq \mathrm{I}$ or $\gamma^{*} \neq-\mathrm{I}$ but the series in (4) are co-integrated, then monetary forces manage to maintain a long-run relationship between exchange rates and prices. Real economic variables may indeed have a deterministic influence on the relative price of traded goods in each country, but exchange rates and prices are still held together in the long run.

\section{STATISTIGAL PROPERTIES OF THE ESTIMATORS}

Because the statistics are described fully in Park (I990), we shall give here only a cursory discussion of the various estimators. The tests are based on the variable addition approach; they are easy to implement and flexible enough to deal with series containing both deterministic and stochastic trends. All the other tests for co-integration, including those developed by Engle and Granger (I987) and Johansen (I988), take the absence of co-integration as the null hypothesis.

The variable addition approach simply adds superfluous time polynomials and tests whether the added terms are significant. If the regression has stationary errors, the usual Wald test should be able to detect that the added regressors are indeed superfluous. If the regression has integrated errors, then it is spurious, as shown in Granger and Newbold (1974). In this case, the Wald statistic diverges and the added regressors would seem incorrectly to be significant.

Park's ( I 990) approach yields two types of statistics. The $J_{1}$ statistic is based upon the null of co-integration or, equivalently, that the residuals from the cointegrating regression in levels are stationary. If applied to a single series, it tests 
the null of stationarity. Let $p$ and $q$ be non-negative integers, with $p<q$. The $J_{1}(p, q)$ statistic is calculated maintaining that the deterministic trend is a $p$-th order polynomial, while $q-p$ terms of higher order polynomial terms are added to test for the correctness of the specification of the regression. Park (I990) shows that the $J_{1}(p, q)$ statistic is distributed asymptotically $\chi^{2}(p-q)$.

The $J_{2}$ statistic can be used for the more conventional null hypothesis of a unit root or no co-integration. Again, the notation $J_{2}(p, q)$ makes explicit the maintained order of the time trend and the number of superfluously added time polynomials. The $J_{2}$ statistic is computationally simpler than $J_{1}$, but it has a non-standard limiting distribution. The critical values are tabulated in Park and Choi (I988) and Park et al. (1988), for the tests of unit roots and cointegration respectively. Both the $J_{1}$ and $J_{2}$ statistics are non-parametric, and they are valid for a very wide class of data-generating mechanisms. In particular, it is possible for the underlying series to exhibit serial correlation and heterogeneity.

We also test whether the real exchange rates are stationary. Under the null hypothesis of co-integration, this implies that the coefficients of the regressors in (4) are given by $(\mathrm{I},-\mathrm{I})^{\prime}$. The test uses the method of Canonical Cointegrating Regression developed by Park (I99I). It is non-parametric, and it is asymptotically equivalent to the exact maximum likelihood method of Johansen ( 1988 ) when the underlying model is given by a finite order vector auto-regression.

\section{THE EMPIRICAL RESULTS}

We examine the consumer price indices, wholesale price indices, and bilateral exchange rates of the eleven major industrial countries; these economies are called, ironically, the G-Io countries. They are Belgium, Canada, France, Germany, Italy, Japan, the Netherlands, Sweden, Switzerland, the United Kingdom, and the United States. The data are sampled monthly; the consumer price indices are reported by the Federal Reserve Board and are not seasonally adjusted, ${ }^{2}$ the wholesale price indices are reported by the International Monetary Fund, and the exchange rates are noon quotes from the New York market on the last business day of the month, also reported by the Federal Reserve Board. These data give rise to fifty-five different bilateral exchange rates. The first observation is in March I973 and the final observation is in May $1988 .^{3}$

As a first step in the analysis, we tested the exchange rates and price indices. The model implies that these series all have unit roots and deterministic linear trends; hence, we used the $J_{2}(\mathrm{I}, 5)$ statistic. In the cases of the fifty-five exchange rate series, we were able to reject the null of a unit root for a test of size $5 \%$ in six cases. Considering the size of this test, we take this as evidence

\footnotetext{
2 Many of the European countries have administered price increases at semi-annual frequencies. Since there is little reason to believe that a long-run equilibrium relationship between prices and exchange rate has a seasonal factor, we treated the seasonal components of inflation as nuisance parameters.

3 The French wholesale price index runs only to December 1985 .
} 
that de-trended logarithmic exchange rates do have unit roots. We conducted the same tests for the consumer and wholesale price indices; we were not able to reject in any case that the de-trended price series had unit roots.

The next step was the test for co-integration. Since the null hypothesis is that the series are co-integrated, we used the $J_{1}(0,3)$ statistic. Notice that we interpret co-integration in a stricter sense than is usual in the literature; we tested co-integration of the stochastic components in the sense of Engle and Granger ( 1987 ) and the co-trending of the individual deterministic components. ${ }^{4}$ Table I summarises the results.

Table I

Co-integration of Exchange Rates Prices

$\left(\mathrm{J}_{1}(\mathrm{o}, 3)\right.$ Co-integrating Statistic, 24 Lags for the Parzen Window)

\begin{tabular}{lccccccccccc}
\hline \hline & $\mathrm{BE}$ & $\mathrm{CA}$ & $\mathrm{FR}$ & $\mathrm{GE}$ & $\mathrm{IT}$ & $\mathrm{JA}$ & $\mathrm{NE}$ & $\mathrm{SD}$ & $\mathrm{SZ}$ & $\mathrm{UK}$ & $\mathrm{US}$ \\
\hline $\mathrm{BE}$ & -- & $*$ & $\dagger \dagger$ & $* * \dagger \dagger$ & $\dagger \dagger$ & & $\dagger \dagger$ & & $\dagger \dagger$ & & $* * \dagger \dagger$ \\
$\mathrm{CA}$ & & -- & & & $* \dagger \dagger$ & $* *$ & $* * \dagger$ & $\dagger \dagger$ & $* * \dagger$ & $* *$ & $* *$ \\
$\mathrm{FR}$ & & & -- & $\dagger$ & $\dagger \dagger$ & & & & $\dagger \dagger$ & & \\
$\mathrm{GE}$ & & & & -- & & & $\dagger \dagger$ & & & & $* \dagger \dagger$ \\
$\mathrm{IT}$ & & & & & -- & $* * \dagger$ & $*$ & $\dagger$ & & $* * \dagger$ & $* * \dagger \dagger$ \\
$\mathrm{JA}$ & & & & & & -- & & & & $* *$ & $* *$ \\
$\mathrm{NE}$ & & & & & & & -- & $\dagger$ & & & $* * \dagger$ \\
$\mathrm{SD}$ & & & & & & & & -- & & $* *$ & $* * \dagger \dagger$ \\
$\mathrm{SZ}$ & & & & & & & & & -- & $*$ & $* * \dagger \dagger$ \\
$\mathrm{UK}$ & & & & & & & & & & -- & $\dagger$ \\
\hline \hline
\end{tabular}

* Reject for consumer prices at the $5 \%$ significance level.

** Reject for consumer prices at the $\mathrm{I} \%$ significance level.

$\dagger$ Reject for wholesale prices at the $5 \%$ significance level.

$\dagger \dagger$ Reject for wholesale prices at the I \% significance level.

The table can be read as follows. The eleven currencies define one hundred and ten bilateral exchange rates. Since half of these exchange rates are the reciprocals of the other half, there are effectively fifty-five bilateral exchange rates. These are presented in the upper right half of the table, and the symbols represent rejections of the null of co-integration.

This evidence is striking. There is almost no evidence that the United States' dollar bilateral exchange rate has been co-integrated with the relevant consumer price indices. Excluding the North American currencies from consideration, one cannot reject the hypothesis that twenty-eight of the thirtysix remaining currencies are co-integrated with the consumer prices. The tests using wholesale prices confirm these findings. There is evidence of co-

\footnotetext{
${ }^{4}$ Since the $J_{1}(0,3)$ statistic may be sensitive with respect to the number of lags used to estimate the Parzen window, we ran these tests using 6, I 2, I $8,24,30$, and 36 lags. The statistics were stable after 24 lags.
} 
integration in twenty-three of the possible thirty-six bilateral relationships not involving Canada or the United States. The currencies of Belgium and Italy, both members of the European Monetary System, fare poorly in the tests using wholesale prices.

In order to check whether these results are an artifact of the null hypothesis, we ran a second series of tests based upon the $J_{2}(0,3)$ statistic. For the sake of brevity, we do not report these statistics. They exhibit largely the same pattern. One cannot reject the null hypothesis that the United States' bilateral exchange rates are not co-integrated with the relevant consumer price indices; this is also true using wholesale prices for ten of the eleven cases involving the United States.

The sign pattern of the normalised co-integrating vector ought to be ( $\mathrm{I},+$, $-)^{\prime}$. For those cases where there was strong evidence of co-integration, we did not find that every sign pattern was as such, but a vast majority of the cointegrating vectors did exhibit this pattern in the tests based upon consumer prices indices. Every sign pattern was correct for wholesale prices.

We conclude this section by describing the results from the test based upon the null hypothesis that the normalised co-integrating vector is $(I, I,-I)^{\prime}$; this is a test for stationary real exchange rates. Again, for the sake of brevity, we do not report the values of all fifty-five test statistics. Using twenty-four lags to estimate the Parzen window, we reject this null hypothesis in forty-three of the fifty-five cases involving consumer prices; almost every rejection has an enormously high marginal significance. We reject the same hypothesis in fiftyone of fifty-five of the cases involving wholesale prices.

\section{THE ERROR GORREGTION MECHANISMS}

We estimated error correction mechanisms for all thirty-four country pairs for which we could not reject the hypothesis of co-integration using consumer prices and for all thirty-one similar cases involving wholesale prices. Let $\mathbf{y}_{t}$ be $\left(e_{t}-e_{t-1}, p_{t}-p_{t-1}, \quad p_{t}^{*}-p_{t-1}^{*}\right)^{\prime}$, and consider the residual $x_{t-1}=e_{t-1}-\hat{\gamma} p_{t-1}-\hat{\gamma}^{*} p_{t-1}^{*},{ }^{5}$ where the estimate is based upon equation $(4)$ and is done with de-trended series. We estimated the following system of equations

$$
\mathbf{y}_{t}=-\lambda x_{t-1}+\boldsymbol{\beta}_{0}+\sum_{i=1}^{12} \mathbf{B}_{i} \mathbf{y}_{t-i}+\mathbf{v}_{t}
$$

where $\lambda$ and $\boldsymbol{\beta}_{0}$ are $3 \times$ I vectors, each $\mathbf{B}_{i}$ is a $3 \times 3$ matrix, and $\mathbf{v}_{t}$ is a $3 \times \mathrm{I}$ vector of error terms. It is convenient to call $x_{t-1}$ the equilibrium error for the system. The first row of (5) describes the dynamic adjustment of exchange rates, and its second and third rows model those of domestic prices and foreign prices respectively.

Under the null hypothesis of co-integration, these regressions contain only

5 In an earlier version of this paper, we explored whether each co-integrating vector was unique. We found overwhelming evidence that this was the case for almost all country pairs. That is why we used a unique equilibrium error in estimating the error correction mechanism. 
stationary variables and can be analysed in the usual way. We are particularly interested in the elements of the vector $\lambda$. We report estimates of these coefficients using consumer prices in Table 2.

Table 2

Coefficients on the Equilibrium Error Terms for Consumer Prices

\begin{tabular}{|c|c|c|c|}
\hline Country Pair & $-\lambda_{1}$ & $-\lambda_{2}$ & $-\lambda_{3}$ \\
\hline Belgium-France & $-0 \cdot 15240^{* *}$ & $\mathrm{o} \cdot \mathrm{I}_{4} 657 \mathrm{E}-\mathrm{OI}$ & $-0.1555^{\mathrm{IE}-\mathrm{O} 2}$ \\
\hline Belgium-Italy & $-\mathrm{o} \cdot \mathrm{I} 9559 \mathrm{E}-\mathrm{OI}$ & $0.68643 \mathrm{E}-04$ & $=-O \cdot{ }_{1} \mathrm{I}_{4}{ }_{4} \mathrm{E}-\mathrm{OI}$ \\
\hline Belgium-Japan & $-0.20378 * *$ & 0.6048 I E-02 & $-0.1927 \mathrm{IE}-\mathrm{OI}$ \\
\hline Belgium-Netherlands & -0.8 I $098 \mathrm{E}-\mathrm{OI} * *$ & $\mathrm{o}^{\prime} 35^{6} 5^{8 \mathrm{E}-\mathrm{OI} *}$ & -0.267 I $8 E-01$ \\
\hline Belgium-Sweden & $-0.76543 \mathrm{E}-\mathrm{OI} *$ & $-0.35946 \mathrm{E}-02$ & $-\mathrm{o} \cdot \mathrm{I} 788 \mathrm{oE}-\mathrm{OI}$ \\
\hline Belgium-Switzerland & -o. I $3249^{* *}$ & $0.76786 \mathrm{E}-02$ & $-\mathrm{o}^{\circ} 34^{6} 34^{\mathrm{E}-\mathrm{o} 3}$ \\
\hline Belgium-United Kingdom & $-0.324 \mathrm{OIE}-\mathrm{OI}$ & O. I 79 I I E-O2 & -0.12 I $37 \mathrm{E}-\mathrm{OI}$ \\
\hline Canada-France & $-0.51906 \mathrm{E}-\mathrm{OI}$ & $0.54736 \mathrm{E}-02 *$ & $0 \cdot{ }_{1} 6637 \mathrm{E}-02$ \\
\hline Canada-Germany & $-0.43320 \mathrm{E}-\mathrm{OI}$ & $0.63536 \mathrm{E}-02 *$ & $0.91568 \mathrm{E}-03$ \\
\hline Canada-Sweden & -0.27 I $48 \mathrm{E}-\mathrm{OI}$ & $0.37866 \mathrm{E}-02$ & 0.2 I I $48 \mathrm{E}-02$ \\
\hline Canada-United Kingdom & $-0.52896 \mathrm{E}-\mathrm{OI} *$ & $\mathrm{O} \cdot \mathrm{I} 8265 \mathrm{E}-\mathrm{O} 2$ & $\mathrm{O} \cdot \mathrm{I}_{6557 \mathrm{E}-\mathrm{O} 2}$ \\
\hline Canada-United States & $-0.9856 \mathrm{oE}-\mathrm{OI} *$ & $-0.6848 \mathrm{I} E-02$ & 0.29 I I $0 E-02$ \\
\hline France-Germany & $-0.1347 \mathrm{I} * *$ & $-0 \cdot 38043 \mathrm{E}-03$ & $-0.4776{ }_{3} \mathrm{E}-02$ \\
\hline France-Italy & $-0.70662 \mathrm{E}-\mathrm{OI} *$ & $-0.42323 \mathrm{E}-02$ & $-0.2892 \mathrm{I} \mathrm{E}-\mathrm{OI} * *$ \\
\hline France-Japan & $-0.13728 *$ & $-0.21400 E-02$ & $-0.50244 \mathrm{E}-02 * *$ \\
\hline France-Netherlands & $-0.12587 * *$ & $0.51772 \mathrm{E}-03$ & $0 \cdot 46400 \mathrm{O}-\mathrm{O} 2$ \\
\hline France-Sweden & $-0.17373^{* *}$ & $-\mathrm{O} \cdot \mathrm{I}_{0} \mathrm{O}_{3} \mathrm{E}-\mathrm{OI}$ & $-0.1876 \mathrm{oE}-\mathrm{OI}$ \\
\hline France-Switzerland & -o.1 I $939 * *$ & 0.2432 I E-02 & $-0.43997 \mathrm{E}-02$ \\
\hline Germany-Italy & $-0.20180 E-02$ & $-0.95070 \mathrm{E}-\mathrm{O} 3$ & $-0.24693^{\mathrm{E}}-\mathrm{OI} * *$ \\
\hline Germany-Japan & $-0.23407^{* *}$ & $-0.49326 \mathrm{E}-02$ & $-0.3756 \mathrm{I}$ E-02 \\
\hline Germany-Netherlands & $-0.19874^{* *}$ & $-0.55^{\mathrm{I}} 5^{2 \mathrm{E}-\mathrm{OI}} *$ & $-0 \cdot 179$ I $8 \mathrm{E}-\mathrm{OI}$ \\
\hline Germany-Sweden & $-0 \cdot 10884^{* *}$ & $-0.24354 \mathrm{E}-02$ & $-0 \cdot 15606 \mathrm{E}-\mathrm{OI}$ \\
\hline Germany-Switzerland & $-0.20657^{* *}$ & o.99342E-02 & $-0 \cdot 1086 \mathrm{I} E-0 \mathrm{I}$ \\
\hline Germany-United Kingdom & $-0.47962 \mathrm{E}-\mathrm{OI}$ & O. I 049 IE-O2 & $-0.875_{21 E} \mathrm{IE}-02$ \\
\hline Italy-Japan & $-0 \cdot 14798 * *$ & $0.65742 \mathrm{E}-\mathrm{O} 3$ & -0.42 I $43 \mathrm{E}-02$ \\
\hline Italy-Switzerland & $-0.509{ }_{14} \mathrm{E}-\mathrm{OI}$ & $0.18702 \mathrm{E}-\mathrm{OI} *$ & $-0.60882 \mathrm{E}-02$ \\
\hline Japan-Netherlands & $-0.21508 * *$ & $\mathrm{o} \cdot 2096{ }_{3} \mathrm{E}-\mathrm{OI} *$ & $0.43495^{\mathrm{E}-02}$ \\
\hline Japan-Sweden & $-0.1205^{6 * *}$ & - O. I I $786 \mathrm{E}-02$ & $-0.54^{2} 9^{8} \mathrm{E}-03$ \\
\hline Japan-Switzerland & -o. I $734^{6 * *}$ & $\mathrm{O} \cdot \mathrm{I}_{4}^{8} 5^{2 \mathrm{E}}-\mathrm{OI}$ & o. I I I $69 \mathrm{E}-02$ \\
\hline Netherlands-Sweden & - 0 I I 78 I $* *$ & $-0.6336{ }_{3} \mathrm{E}-02$ & $-\mathrm{O} .17724 \mathrm{E}-\mathrm{OI}$ \\
\hline Netherlands-Switzerland & $-0.2723^{8 * *}$ & O. I O8 ogE-OI & $-0.81324 \mathrm{E}-02$ \\
\hline Netherlands-United Kingdom & $-0.29602 \mathrm{E}-\mathrm{OI}$ & $\mathrm{O} \cdot 155^{25} \mathrm{E}-02$ & $-0.69602 \mathrm{E}-02$ \\
\hline Sweden-Switzerland & $-0.98468 \mathrm{E}-\mathrm{OI} *$ & O. I6399E-OI * & $-0.2053^{6 E}-02$ \\
\hline United Kingdom-United States & $-\mathrm{O} .52382 \mathrm{E}-\mathrm{OI}$ & 0.878 г $8 \mathrm{E}-03$ & $-0.80404 \mathrm{E}-02$ \\
\hline
\end{tabular}

* Significantly different from zero at the $5 \%$ significance level.

** Significantly different from zero at the I \% significance level.

These results are quite remarkable. The error correction for the system makes itself manifest largely in the equation having to do with the exchange rate. Twenty-four of the thirty-four terms are significantly different from zero at the $5 \%$ level, and there were several cases where the marginal significance level was quite close to $5 \%$. The sign of the estimate of $-\lambda_{1}$ is uniformly negative, and most of the estimates are of the same order of magnitude. The effects on domestic and foreign prices seem largely to be insignificant. The general sign patterns of $-\lambda_{2}$ and $-\lambda_{3}$ show that a real devaluation has a slight tendency to cause domestic inflation and foreign deflation. 
The estimated equations using wholesale price indices were similar, although there was some evidence that the dynamic adjustment to a shock occurs in the foreign price equation in the case of Britain. This may have to do with the relationship between the pound sterling and the price of oil.

This analysis suggests that each of these countries conducts an independent monetary policy and that the market for foreign exchange holds exchange rates and prices together in the long run. Indeed, the estimates of $\lambda_{1}$ indicate that a I0\% real depreciation of any of these exchange rates gives rise to an appreciation of the nominal exchange rate of roughly I $\%$ or $2 \%$ in the next month. This is strong evidence that these exchange rates display the property of overshooting.

\section{GONGLUSION}

This paper presented tests of purchasing power parity that used the null hypothesis of co-integration. It found support for a simple model of exchange rates and prices in the large majority of cases involving neither the American dollar nor the Canadian dollar. Perhaps the fact that the United States dollar is the key currency in the international monetary system has cut the link between its value and measures of inflation. Still, monetary forces keep the exchange rates of most other major currencies in line with underlying price differentials.

The estimation of the error correction mechanisms showed that asset markets, not goods markets, affect the necessary adjustment to disequilibrium. There was surprisingly little evidence that these real exchange rates were stationary. We conclude that unobservable real economic variables have changed the relative price of traded goods to non-traded goods in the major industrial countries over the modern period of floating exchange rates.

\section{REFERENGES}

Baillie, Richard, T. and Bollersley, Tim (1989). 'Common stochastic trends in a system of exchange rates.' Journal of Finance, vol. 44, pp. I67-8I.

Cassel, G. (igi6). 'The present situation of the foreign exchanges.' Economic Journal, vol. 26, pp. 62-5.

Corbae, Dean and Ouliaris, Sam (1986). 'Robust tests for unit roots in the foreign exchange market.' Economics Letters, vol. 22, pp. 375-8o.

Edison, Hali J. and Fisher, Eric O'N. (I99I). 'A long-run view of the European Monetary System.' Journal of International Money and Finance, vol. io, pp. 53-70.

Enders, Walter ( 1988 ). 'ARIMA and cointegration tests of purchasing power parity under flexible and fixed exchange rate regimes.' Review of Economics and Statistics, vol. 70, pp. 504-8.

Engle, Robert and Granger, C. W. J. ( 1987 ). 'Forecasting and testing in co-integrated systems.' Econometrica, vol. 35, pp. 143-6o.

Frenkel, Jacob A. (I981). 'Flexible exchange rates, prices, and the role of news: lessons from the i $970 s . '$ Journal of Political Economy, vol. 89, pp. 665-705.

Granger, C. W. J. and Newbold, Paul (I 974). 'Spurious regressions in econometrics.' Journal of Econometrics, vol. 2, pp. I I I-20.

Isard, Peter (1977). 'How far can we push the Law of One Price?' American Economic Review, vol. 67, pp. $942-8$. 
Johansen, Søren (1988). 'Statistical analysis of cointegration factors.' Journal of Economic Dynamics and Control, vol. I2, pp. $23^{1-54}$.

Meese, Richard A. and Singleton, Kenneth J. ( 1982 ). 'On unit roots and the empirical modeling of exchange rates.' Journal of Finance, vol. 37, pp. I029-35.

Park, Joon Y. (1990). 'Testing for unit roots and cointegration by variable addition.' In Cointegration, Spurious Regression, and Unit Roots: Advances in Econometrics (ed. Thomas B. Formby and George F. Rhodes, Jr.). Greenwich, Connecticut and London: JAI Press.

- (1991). 'Canonical cointegrating regressions.' Econometrica (forthcoming). and Choi, Buhmsoo (1988). 'A new approach to testing for a unit root.' CAE Working Paper no 88-23, Cornell University.

- Ouliaris, Sam and Choi, Buhmsoo (1988). 'Spurious regression and tests for co-integration.' CAE Working Paper no. 88-07, Cornell University. 